\title{
Pemanfaatan Rinfogroup Sebagai Media Diskusi dan Penilaian Keaktifan Mahasiswa
}

\section{Rinfogroup Use as Media Discussion and Assessment of Student Activity}

\author{
Untung Rahardja', Eka Purnama Harahap ${ }^{2}$, Dwi Anjani ${ }^{3}$ \\ Dosen Sistem Informasi STMIK Raharja ${ }^{1}$, Dosen Sistem Informasi STMIK Raharja ${ }^{2}$, Mahasiswa \\ Sistem Informasi STMIK Raharja ${ }^{3}$ \\ Jl. Jendral Sudirman No. 40 Modern Cikokol, Tangerang Tel/Fax : (021)5529692 \\ *11 untung@ raharja.info, ${ }^{2}$ ekapurnamaharahap@ raharja.info, ${ }^{3}$ dwi.anjani@ raharja.info
}

\begin{abstract}
Abstrak
Pada Perguruan Tinggi Raharja, setiap civitas akademika diberikan fasilitas berupa email resmi yaitu Rinfo yang digunakan sebagai media komunikasi. Namun saat ini belum tersedia wadah untuk berdiskusi antara mahasiswa dan dosen, sehingga proses diskusi pembelajaran belum efektif dan efisien karena masih dilakukan secara tatap muka. Oleh karena itu, diperlukannya pemanfaatan RinfoApps yang dapat digunakan sebagai wadah diskusi pembelajaran online. RinfoGroups merupakan salah satu Google System dapat dimanfaatkan sebagai wadah formal untuk proses diskusi pembelajaran online. Dengan membuat milis kelas pada RinfoGroups, mahasiswa dan dosen dapat berdiskusi di luar jam perkuliahan, dosen dapat sharing mengenai bahan materi pembelajaran, serta dosen dapat memantau keatifan berdiskusi mahasiswa. Dalam penelitian ini, ditemukan 3 (tiga) permasalahan pada sistem yang ada sebelumnya. Lalu dengan didukung 2 (dua) metode penelitian yaitu metode observasi dan studi pustaka. Hasil akhir yang di capai dari penelitian ini yaitu terbentuknya media diskusi yang dapat di akses dimana dan kapan saja sehingga proses diskusi antara mahasiswa dan dosen menjadi lebih efektif dan efisien.
\end{abstract}

Kata kunci-Komunikasi, Email, RinfoGroups, Diskusi

\begin{abstract}
In raharja, every academic facilities such as the official email Rinfo is used as media communication. But is not currently available media for online discussions, so that the learning process has not been effective discussion and efficient because they do face to face. Therefore, it is necessary to use RinfoApps which can be used as a discussion. RinfoGroups is one of the Google system can be used as a forum discussion online. By creating a mailing list on RinfoGroups, students and lectures can discuss outside of the class hours, lecturer can share about learning materials, and also can monitor student discussions activity. In this study, it was found 3 (three) problems in the system that existed before. Then supported by 2 (two) research method that is observation method and literature study. The final results are achieved from this research that the forum of discussion media that can be accessed anywhere and at any time so that the process of discussion become more effective and efficient.
\end{abstract}

Keywords - Communication, Email, RinfoGroups, Discussion

\section{PENDAHULUAN}

Komunikasi merupakan suatu proses menyampaikan pesan, bertanya, memberi informasi ataupun bertukar pendapat yang di lakukan oleh dua orang atau lebih. Kegiatan komunikasi bisa di lakukan secara langsung ataupun tidak langsung dengan memanfaatkan alatalat teknologi. Tersedianya layanan akses internet yang mudah dan cepat juga semakin 
membuat proses komunikasi semakin efektif dan efisien. Salah satu fasilitas yang dapat digunakan untuk mendukung proses komunikasi yaitu dengan memanfaatkan teknologi dari Google System dalam kegiatan perkuliahan.

Perguruan Tinggi Raharja merupakan salah satu perguruan tinggi swasta di Tangerang yang bergerak dalam bidang ilmu komputer dan teknologi informasi, telah menciptakan metode pembelajaran baru yang bernama iLearning. Metode pembelajaran iLearning merupakan konsep media pembelajaran yang pertama kali dicetuskan pada tahun 2009 oleh Ir.Untung Rahardja, M.T.I .,MM dengan menggunakan media iPad (iLearning with iPad). Dan pengertian iLearning menurut beliau yaitu 4B (Belajar, Bermain, Berdoa, Bekerja)'. Dalam metode pembelajaran iLearning terdapat sepuluh fitur-fitur penunjang pembelajaran yang terangkum dalam TPi (Ten pilar IT learning).

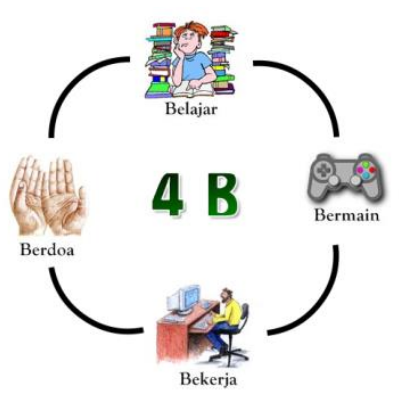

Gambar 1. Logo iLearning

Rinfo merupakan salah satu dari TPi (Ten pilar IT learning) yang berfungsi sebagai kunci untuk bisa terhubung dengan kesembilan pilar lainnya. Selain itu, Rinfo digunakan sebagai email resmi untuk mahasiswa, dosen dan juga staf yang digunakan sebagai media komunikasi utama. Akan tetapi pemanfaatan Rinfo sebagai media komunikasi masih kurang efektif. Misalnya dalam proses diskusi sehari-hari yang berlangsung di dalam kelas antara mahasiswa dan dosen saat ini masih berlangsung secara tatap muka atau face to face. Proses diskusi, bertukar informasi, atau bertanya masih di lakukan secara langsung dan belum memanfaat Rinfo sebagai media komunikasi.

Pada penelitian yang sebelumnya dilakukan oleh Aris Martono, Padeli dan Rosalina Miliartha pada tahun 2016 yang berjudul "Rancang-Bangun Aplikasi Sistem Diskusi Pembelajaran Online Pada Perguruan Tinggi." Penelitian ini membahas mengenai forum diskusi online yang disajikan dalam bentuk web, yang nantinya sistem diskusi online ini di peruntukan kelas reguler atau non ilearning. Manfaat penelitian yaitu dapat mempermudah proses komunikasi pembelajaran antara dosen dan mahasiswa ${ }^{2}$. Penelitian selanjutnya oleh Agus Putranto dari Universitas Bina pada tahun 2012 yang berjudul "Perancangan Forum Diskusi Mobile Online Learning". Penelitian ini membahas tentang forum diskusi pada media $E$ learning disajikan dalam bentuk mobile. Salah satu fitur yang penting dalam kegiatan belajar mengajar adalah forum diskusi. Hasil dari penelitian ini yaitu mahasiswa dan dosen dapat dengan mudah mengakses forum diskusi dengan mengakses m-learning, mahasiswa juga dapat mengunduh bahan materi perkuliahan dan mendapatkan informasi seputar perkuliahan ${ }^{3}$. Penelitian selanjutnya oleh Dewi Immaniar Desrianti, Lusyani Sunarya, dan Dwi Fitri Permania pada tahun 2015 yang berjudul "Pemanfaatan Teknologi Komunikasi Dan Informasi (TIK) Pada Rhjfox Sebagai Forum Diskusi". Penelitian ini membahas tentang Forum Diskusi online yang di beri Nama Rhjfox yang digunakan sebagai wadah berkomunikasi dengan tujuan memberi pendapat, motivasi, solusi, dan informasi terkait dengan pembahasan yang sedang berlangsung. Dengan memanfaatkan Rhjfox, kegiatan berdiskusi dapat dilakukan dimana dan kapan saja asalkan terkoneksi dengan internet sehingga mahasiswa dan dosen dapat berdiskusi tanpa harus bertatap muka sehingga lebih efektif dan efisien ${ }^{4}$. 
Terdapat 3 (tiga) perbedaan penelitian ini dari ketiga penelitian yang telah diuraikan di atas. Perbedaan pertama yaitu penelitian ini memanfaatkan salah satu fitur dari Google System yaitu RinfoGroups sedangkan dari ketiga penelitian di atas menggunakan website dan mobile application sebagai media diskusinya. Perbedaan kedua yaitu pada penelitian sebelumnya media diskusi dirancang untuk di gunakan oleh mahasiswa regular sedangkan pada penelitian ini ditujukan untuk mahasiswa iLearning. Perbedaan yang ketiga yaitu untuk bisa melakukan diskusi mahasiswa hanya perlu membuka inbox Rinfo masing-masing sedangkan pada penelitian sebelumnya mahasiswa harus mengunjungi website atau mempunyai mobile application terlebih dahulu untuk bisa melakukan diskusi.

Proses berdiskusi dalam kelas dilakukan secara langsung atau tatap muka mempunyai 3 (tiga) permasalahan. Permasalahan yang pertama adalah mahasiswa dan dosen kesulitan dalam melakukan proses diskusi di luar kelas atau di luar jam perkuliahan karena belum tersedianya wadah yang dapat digunakan sebagai media diskusi. Permasalahan yang kedua adalah dosen kesulitan menyampaikan informasi baru secara cepat kepada seluruh mahasiswa, dan harus menyampaikan pesan satu persatu kepada mahasiswa. Permasalahan yang ketiga adalah dosen tidak bisa menilai keaktifan mahasiswa dalam berdiskusi secara langsung, khususnya untuk kelas iLearning karena dalam berdiskusi langsung dosen tidak mempunyai data-data mahasiswa mana yang aktif melakukan diskusi jika tidak mencatatnya secara manual sehingga dosen tidak bisa menilai keaktifan diskusi mahasiswa.

Untuk lebih memahami tentang permasalahan serta pemecahan masalah dengan menggunakan RinfoGroups sebagai media diskusi online. Menurut Novak dan Gowin (1985) dalam Suci Yuniati (2013), Peta Konsep merupakan salah satu strategi yang dapat digunakan oleh guru/dosen untuk membimbing mahasiswa menyusun konsep-konsep yang telah dipelajari agar terlihat keterkaitannya satu sama lainnya ${ }^{5}$. Untuk dapat memahami keterkaitan penelitian yang ada, penulis telah menjabarkannya ke dalam mind mapping dibawah ini

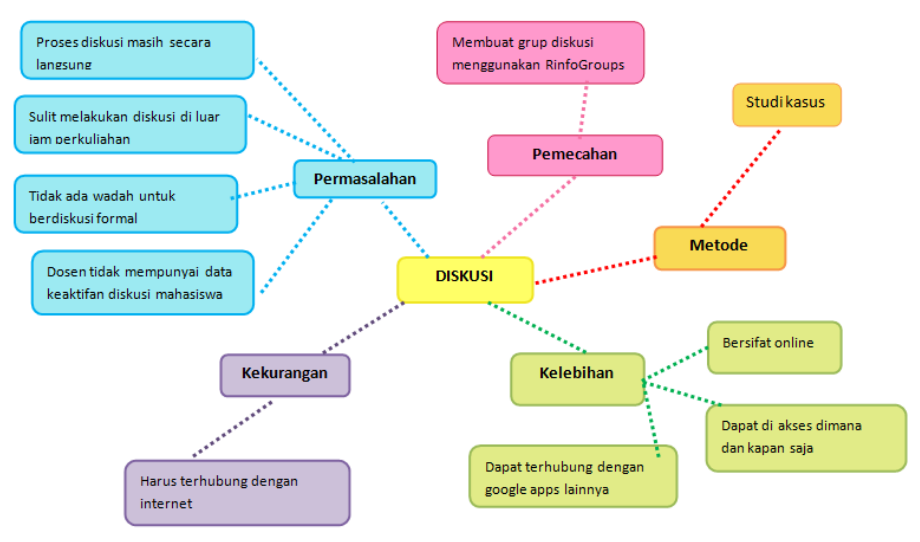

Gambar 2. MindMapping RinfoGroups

Berdasarkan gambar mindmap di atas solusi yang dapat dilakukan dalam proses pemecahan masalah yaitu dengan menggunakan RinfoGroups sebagai media diskusi online dan menggunakan metode studi kasus. Kelebihan yang terdapat dalam RinfoGroups ini yaitu bersifat online sehingga mahasiswa dan dosen dapat berdiskusi di luar jam perkuliahan, serta mempunyai kekurangan yaitu untuk mengakses RinfoGroups, user harus terhubung dengan jaringan internet. Tujuan dari pembuatan mindmap ini yaitu untuk memudahkan penulis dalam melakukan analisa. 


\section{METODE PENELITIAN} berikut:

Terdapat 4 tahapan yang digunakan dalam penyusunan penelitian ini yaitu sebagai

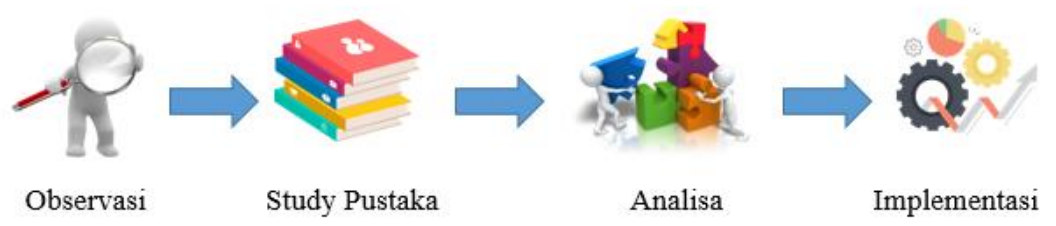

Gambar 3. Metode Penelitian

Keterangan :

a. Metode Observasi

Metode observasi atau pengamatan di lakukan dengan cara melakukan pengamatan langsung kepada proses berjalannya suatu sistem. Tujuan di lakukannya observasi yaitu untuk mendeskripsikan setting yang di pelajari, aktivitas-aktivitas yang berlangsung, orangorang yang terlibat dalam aktivitas dan makna kejadian dilihat dan perpekstif mereka terlibat dalam kejadian yang diamati tersebut ${ }^{6}$. Pada penelitian ini Observasi dilakukan secara langsung pada Perguruan Tinggi Raharja.

b. Metode Study Pustaka

Banyak penelitian yang dilakukan sebelumnya mengenai RinfoGroups bisa dijadikan sumber data. Diantaranya beberapa buku dan penelitian yang dijadikan sumber pustaka, yaitu :

1. Penelitian yang dilakukan oleh Enang Rusnandi dan Deffy Susanti dalam bentuk laporan jurnal Computech \& Bisnis pada tahun 2012 yang berjudul "Perancanaan Strategis Cloud Computing Technology Berbasis Gafe (Google Apps For Education) Bagi Perguruan Tinggi Swasta Di Wilayah III Cirebon Propinsi Jawa Barat).” Penelitian ini membahas mengenai Cloud Computing Technologi yang merupakan salah satu teknologi yang dapat membantu mempermudah organisasi melakukan aktivitas yang berhubungan dengan komunikasi data dan informasi. Tujuan dilakukannya dipenelitian ini yaitu untuk mendapatkan informasi yang akurat mengenai strategi apa saja yang harus disiapkan perguruan tinggi untuk dapat mengadopsi cloud computing technology berbasis GAfE (Google Apps for Education) ${ }^{7}$.

2. Penelitian yang dilakukan oleh Untung Rahardja, Indri Handayani, dan Baiq Aneji Pahad dari Perguruan Tinggi Raharja dalam bentuk laporan jurnal CSRID Vol.8 No.3 Oktober 2016 yang berjudul "Pemanfaatan Rinfoform Sebagai Media Update Artikel Pada iRan". Penelitian ini membahas mengenai pemanfaatan Rinfoform sebagai media pengganti untuk request artikel pada iRan, dari yang sebelumnya masih konvensional (request menggunakan email) menjadi menggunakan Rinfoform. Dengan menggunakan Rinfoform, kegiatan request update artikel menjadi efektif dan efisien serta data dapat terekam dengan baik $^{8}$.

3. Penelitian yang di lakukan oleh Chasfriati Filja, Mardhiah Fadly, dan Syefrida Yulina dari Politeknik Caltex Riau dalam bentuk laporan jurnal Aksara Komputer Terapan Vol.5 No.1 Tahun 2016 yang berjudul "Sistem Informasi Penilaian Partisipasi Mahasiswa Dalam Berdiskusi Secara Online Menggunakan Metode Content Analysis". Penelitian ini bertujuan untuk merancang dan membangun sistem informasi penilaian partisipasi mahasiswa dalam berdiskusi secara online. Metode yang digunakan dalam penelitian ini yaitu metode content analysis yaitu teknik penelitian dalam membuat kesimpulan yang valid berdasarkan isi dengan memperhatikan konteksnya. Jenis pengujian dalam penelitian ini menggunakan metode whitebox texting terhadap kode program QLF dan Rubric ${ }^{9}$. 
4. Penelitian yang dilakukan oleh Indri Handayani, Yessy Oktavyanti, dan Qurotul Aini dari Perguruan Tinggi Raharja dalam bentuk laporan jurnal CCIT Vol. 9 No. 1 Tahun 2015 yang berjudul " Penggunaan RinfoCal Sebagai Aplikasi Pengingat (Reminder) Kegiatan Akademik Pada Perguruan Tinggi”. Penelitian ini mengulas tentang pemanfaatan dari fitur lainnya yang tersedia dalam RinfoApps yang dapat di gunakan sebagai aplikasi pengingat yaitu RinfoCal. RinfoCal dapat digunakan pengguna Rinfo untuk mengingatkan akan jatuh tempo tugas, jadwal bimbingan dan sebagainya. Pada penelitian ini penggunakan RinfoCal sudah di implementasikan sebagai reminder registrasi dan SKS dan banyak lainnya ${ }^{10}$.

5. Penelitian yang dilakukan oleh Indri Handayani, Herrafika Kusumahati dan Alpiah Nurul Badriah dari Perguruan Tinggi Raharja dalam bentuk laporan jurnal SISFOTENIKA VoL.7 No. 2 Tahun 2017 yang berjudul "Pemanfaatan Google Spreadsheet Sebagai Media Pembuatan Dashboard pada Official Site iFacility di Perguruan Tinggi". Pada penelitian ini membahas mengenai penerapan dashboard pelaporan AC pada Official site iFacility dengan menggunakan salah satu fitur google yaitu Google Spreadsheet yang bisa dimanfaatkan untuk menampung data dan mengolah data untuk dijadikan sebuah informasi yang dibutuhkan. Tahapan-tahapan identifikasi Implementasi penelitian dilakukan dengan menggunakan metode observasi, wawancara terhadap divisi operasi, perbandingan sistem, perancangan prototype dan implementasi sistem ke dalam official site iFacility ${ }^{11}$.

Dari 5 (empat) Literature Review yang telah dijelaskan diatas, sudah banyak penelitian yang dilakukan mengenai diskusi online serta ada pula yang membahas forum diskusi pembelajaran online berbasis web, pemanfaatan Rhjfox sebagai forum diskusi mahasiswa dan dosen, Pembuatan fitur forum diskusi pada aplikasi mobile dan bahkan pembuatan sistem informasi untuk penilaian partisipasi mahasiswa dalam diskusi online. Akan tetapi dapat di simpulkan belum ada penelitian yang dilakukan mengenai pemanfaatan RinfoGroups sebagai media diskusi online yang digunakan oleh kelas iLearning di Perguruan Tinggi Raharja.

c. Metode Analisa

Metode yang ketiga yaitu metode analisa. Setelah di analisa proses diskusi yang berjalan pada saat ini masih dilakukan secara manual yang hanya berlangsung ketika matakuliah berlangsung sehingga proses diskusi masih kurang optimal.

d. Implementasi

Pada penelitian ini sudah di lakukan Implementasi dengan menerapkan RinfoGroups sebagai media diskusi online pada mahasiswa bimbingan TimUR 4.

\section{HASIL DAN PEMBAHASAN}

E-mail Rinfo (Raharja info) saat ini telah digunakan sebagai media komunikasi utama yang digunakan oleh pribadi raharja maupun seluruh civitas akademik termasuk staf dan dosen pada perguruan tinggi raharja. RinfoGroups merupakan salah satu fitur dari RinfoApps yang dapat dimanfaatkan sebagai media diskusi online. RinfoGroups sendiri sudah terintegrasi dengan Rinfo sehingga pengguna tidak perlu lagi mendaftar untuk dapat terhubung dengan Milis Groups. Di dalam RinfoGroups kita dapat membuat sebuah milis kelas yang berisikan akun Rinfo seluruh mahasiswa dan dosen yang ada pada sebuah kelas agar seluruh alamat Rinfo tersebut terhimpun dalam sebuah milis grup atau kelompok diskusi dalam sebuah kelas. Dalam mengakses Rinfogroups pun sangat mudah, yaitu dengan login Rinfo dan memasukan nama pengguna dan kata sandi, setelah itu sudah dapat terhubung dengan grup diskusi. Untuk melakukan diskusi pada Rinfogroups, kita hanya perlu login Rinfo dan grup diskusi sudah dapat di akses tanpa harus login berulang kali.

Penggunaan RinfoGroups pada suatu kelas dapat menjadi sebuah wadah atau komunitas formal untuk proses diskusi antara mahasiswa dan dosen di luar jam perkuliahan sehingga proses diskusi dapat diakses dimana saja dan dan saja tanpa terhambat ruang dan waktu. 
Manfaat lain dari RinfoGroups yaitu anggota dalam sebuah grup (dosen atau mahasiswa) dapat memberikan informasi serta mendapatkan informasi secara cepat, akurat, dan sesuai kebutuhan. Dengan menggunakan RinfoGroups, dosen dapat juga memantau keaktifan diskusi mahasiswa dalam sebuah statistik yang tersedia di dalam RinfoGroups yang dapat diakses dalam menu about. Pada menu ini dosen dapat melihat keaktifan dalam sebuah milis kelas dari banyaknya jumlah pesan yang di kirimkan oleh mahasiswa yang ada pada milis kelas tersebut.

Selain manfaat yang telah di uraikan diatas, banyak kelebihan lainnya dari RinfoGroups yang sudah terintegrasi dengan RinfoApps lainnya. Salah satunya dosen dapat memanfaatkan Google Drive yang didalamnya terdapat beberapa aplikasi penunjang pembelajaran seperti Rinfo Docs, Rinfo Slide ataupun Rinfo Spreetsheet yang dapat digunakan untuk menyimpan materi pembelajaran. Kemudian setelah membuat/menyimpan file pada Google Drive dosen bisa sharing di milis mengenai materi perkuliahan dengan membagikan link serta hak akses untuk melihat serta mengunduh materi bahan ajar, sehingga mahasiswa tidak lagi mengalami kesulitan karena pada sistem yang berjalan untuk mengakses materi bahan ajar hanya bisa di lakukan dalam lingkungan kampus dengan memakai wifi lokal yaitu pada fasilitas Raharja Multimedia Edutaiment (RME) .

Setiap pribadi raharja yang ingin masuk menjadi sebuah anggota grup diskusi dalam RinfoGroups harus mempunyai magics key atau Rinfo. Jika belum mempunyai Rinfo, bisa request email Rinfo dengan mengunjungi site http://eco.ilearning.me/ dan mengisi form request email yang tersedia, setelah mengisi form tersebut akan mendapatkan balasan email konfirmasi. Setelah mengisi form request, segera cek email, karena konfirmasi untuk pembuatan Rinfo dilakukan melalui email alternatif dan memerlukan proses paling lambat 2x24jam.

Jika sudah memiliki Rinfo dan telah login, langkah selanjutnya dosen bisa melakukan request milis Rinfo dengan cara mengisi Form Request Milis Rinfo pada http://eco.ilearning.me/ . Setelah mengisi form dengan benar, request milis Rinfo akan di proses oleh admin dan memerlukan proses paling lambat $2 \times 24$ jam.

Pemanfaatan RinfoGroups saat ini telah di pakai sebagai wadah berdiskusi atau komunitas formal (forum) pada kelas iLearning ataupun untuk berbagai grup diskusi yang ada di perguruan tinggi raharja, contohnya sebagai wadah diskusi mahasiswa grup bimbingan TimUr 4. Selain sebagai media diskusi, RinfoGroups dapat di gunakan untuk menilai keaktifan diskusi anggotanya dengan melihat statistik laporan aktivitas yang telah di sediakan RinfoGroups.

a. Tampilang Login Rinfo

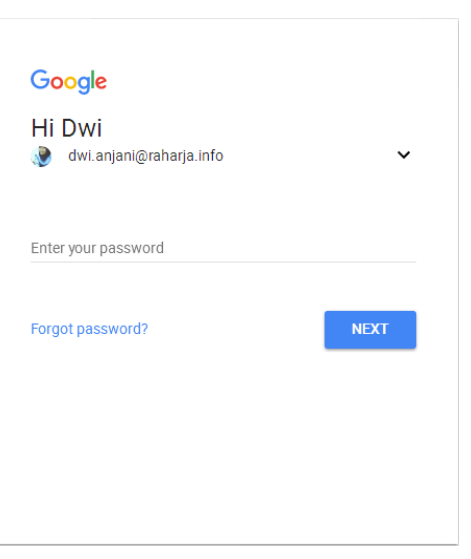

Gambar 4. Halaman Login Rinfo

Merupakan tampilan Login Rinfo untuk dapat terhubung dengan google system. Mahasiswa dan dosen dapat mengakses url http://www.gmail.com agar bisa login dengan mengisi kolom username dan password dengan benar. 
b. Tampilan Halaman Utama Rinfo

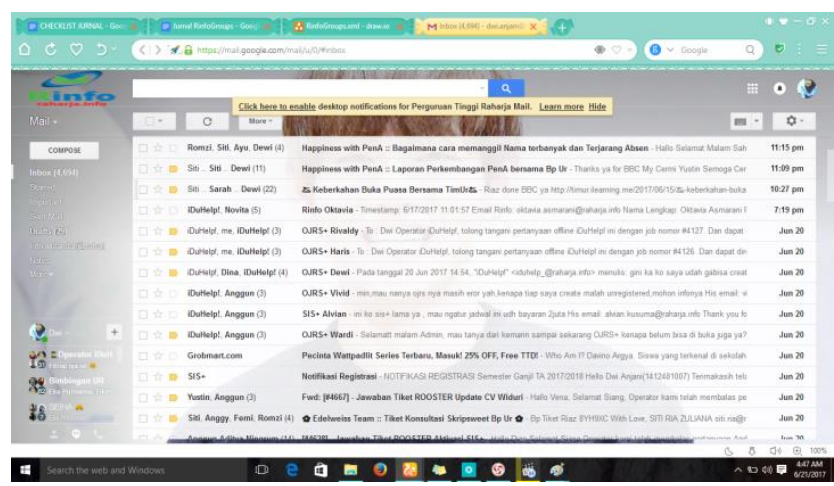

Gambar 5. Halaman Utama Rinfo

Merupakan tampilan utama ketika user berhasil login menggunakan Rinfo. Pada halaman utama tersebut terdapat beberapa menu seperti compose, inbox, outbox, draf, menu setting serta menu untuk mengakses RinfoApps.

c. Tampilan RinfoApps

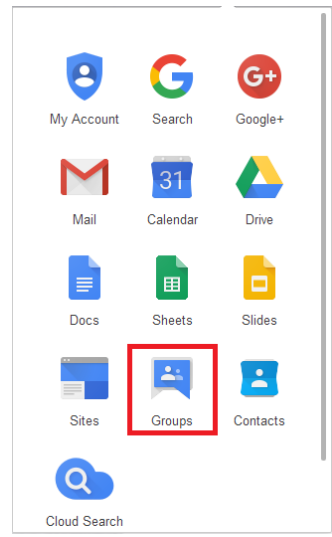

Gambar 6. RinfoApps / Google Apps

Merupakan tampilan kumpulan RinfoApps yang dapat digunakan untuk menunjang sistem pembelajaran, salah satu fasilitas yang dapat digunakan sebagai wadah diskusi pembelajaran yaitu RinfoGroups.

d. Tampilan Menu Home Pada RinfoGroups
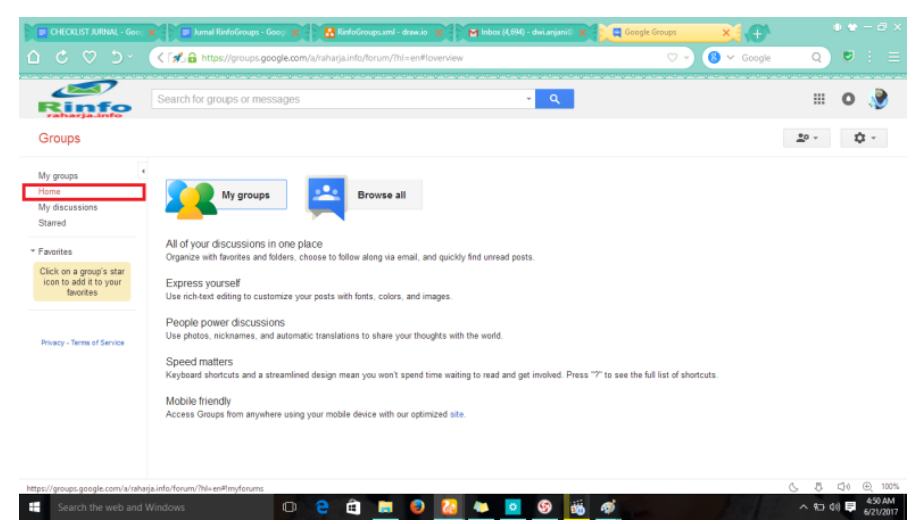

Gambar 7. Menu Home Pada RinfoGroups 
Merupakan tampilan utama / Home pada RinfoGroups. Pada sisi kiri terdapat menu My Group, Home, My Discussion, dan Starred. Pada sisi kanan terdapat foto dari user yang melakukan login dan juga di bawahnya terdapat menu Setting dan menu untuk terhubung dengan RinfoApps lainnya.

e. Tampilan Menu My Group RinfoGroups

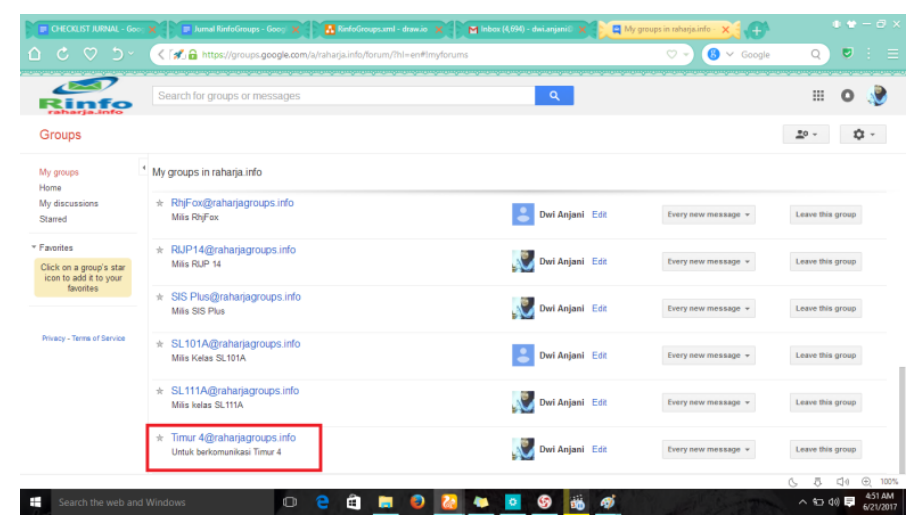

Gambar 8. Menu My Groups

Merupakan tampilan halaman My Groups . Dimana mahasiswa yang telah Login dapat melihat daftar grup dimana mahasiswa tersebut menjadi anggotanya. Pada halaman ini kita dapat membuka grup diskusi dengan meng-klik nama grup yang ingin dibuka.

f. Tampilan Halaman Milis Rinfo

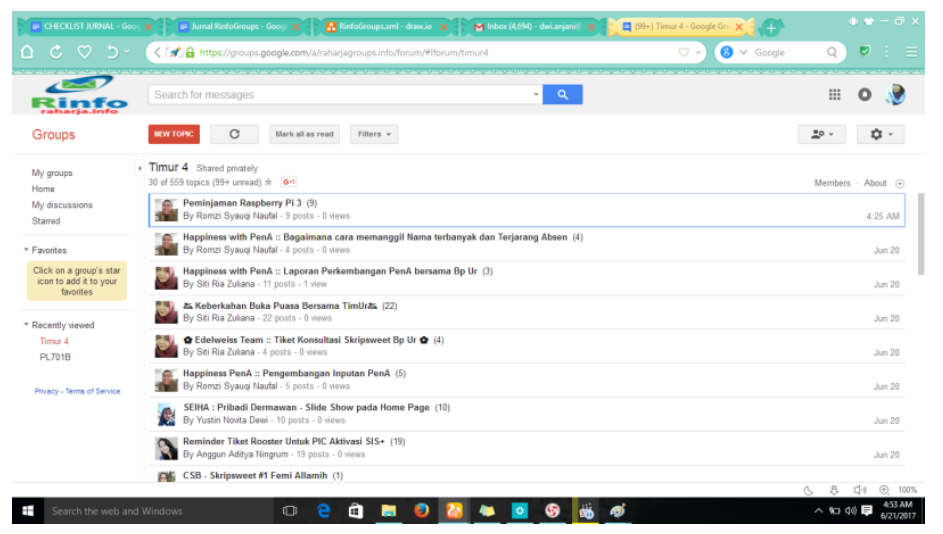

Gambar 9. Halaman Milis Rinfo

Merupakan tampilan utama halaman diskusi pada Milis Rinfo bimbingan TimUr 4. Pada halaman ini terdapat nama pengirim pesan dan subjek dari pesan yang dikirimkan . Pada halaman diskusi ini juga bisa di lihat seberapa banyak respon yang di dapatkan dari pesan yang sudah dikirimkan dan juga tanggal pengiriman respon terakhir yang bisa di lihat pada bagian kanan subjek diskusi.

g. Tampilan Halaman Diskusi RinfoGroups 


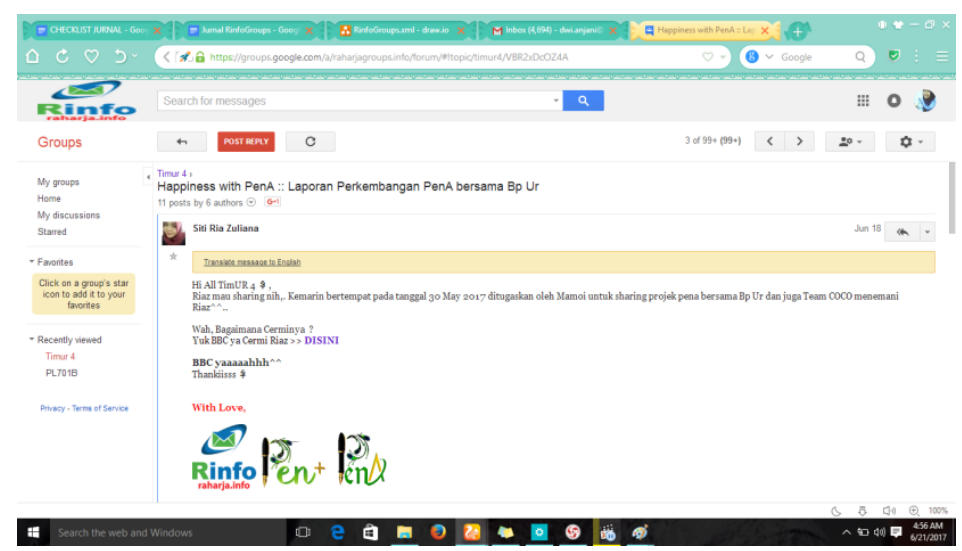

Gambar 10. Halaman Diskusi RinfoGroups

Merupakan tampilan diskusi mahasiswa bimbingan. Pada halaman ini, topik diskusi di uraikan sehingga mahasiswa lainnya ataupun dosen pembimbing dapat mengirimkan komentar ataupun saran mengenai topik yang sedang di bahas.

h. Tampilan Halaman Respons RinfoGroups

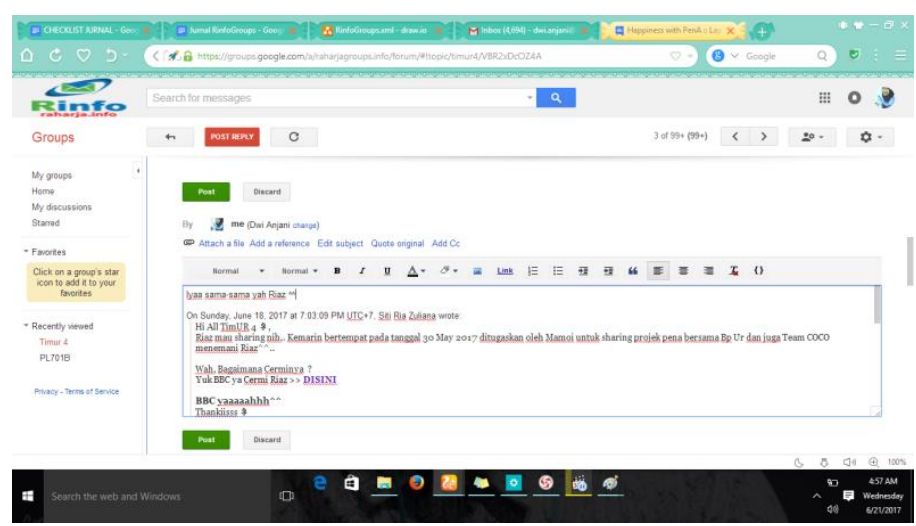

Gambar 11. Halaman Respons RinfoGroups

Merupakan tampilan halaman respons untuk memberikan komentar kepada pengirim topik diskusi. Pada halaman ini. Semua anggota yang terdapat di dalam milis termasuk mahasiswa dan dosen pembimbing dapat mengirimkan respons/komentar mengenai topik diskusi dengan cara Reply All dari pesan tersebut, gunanya agar anggota grup yang lain dapat membaca komentar yang telah diberikan.

i. Tampilan Halaman Members RinfoGroups

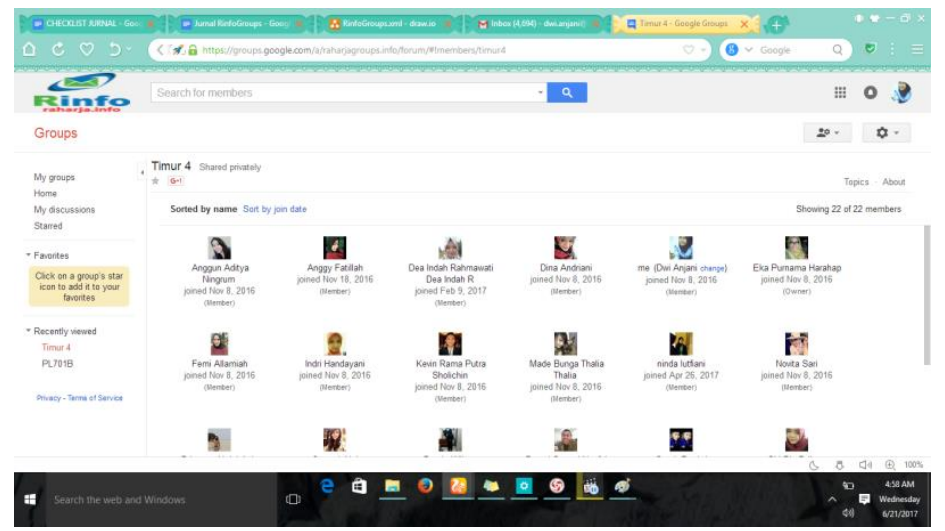




\section{Gambar 12. Halaman Members RinfoGroups}

Merupakan tampilan halaman Members dalam milis Rinfo. Pada halaman ini terdapat daftar nama anggota grup diskusi beserta tanggal masuk anggota tersebut.

\section{J. Tampilan Halaman About RinfoGroups}

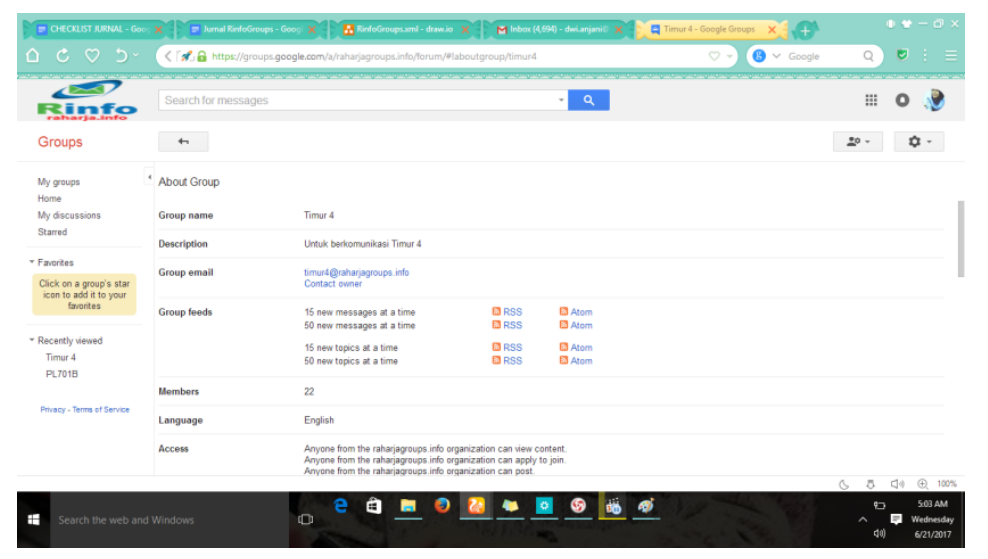

Gambar 13. Halaman about RinfoGroups

Merupakan tampilan halaman yang dapat menampilkan statistik keaktifan anggota dalam sebuah milis grup. Dengan adanya menu About Group, dapat membantu dosen untuk melihat sejauh mana keaktifan mahasiswa dalam berdiskusi karena dalam menu tersebut terdapat jumlah postingan/pesan yang sudah dikirimkan yang di pisahkan menjadi dua menu yaitu : Most Actived Poster keseluruhan dan Most Actived Poster per-bulan.

\section{GRAFIK PENCAPAIAN}

1. Dengan adanya implementasi ini proses berdiskusi pembelajaran dosen dan mahasiswa dapat di lakukan secara online, dan bisa dilakukan dimana saja dan kapan saja di luar jam perkuliahan.

2. Dengan adanya implementasi ini mahasiswa dan dosen tidak perlu lagi mendaftar untuk dapat menjadi anggota sebuah grup diskusi, melainkan hanya login menggunakan Rinfo maka sudah dapat terhubung dengan grup diskusi.

3. Dengan adanya implementasi ini memudahkan dosen dalam menyampaikan informasi secara cepat dan akurat, sehingga bisa di terima cepat pula oleh mahasiswa.

4. Dengan adanya implementasi ini, memungkinkan dosen untuk sharing mengenai bahan materi pembelajaran yang disimpan dalam Google drive agar bisa di unduh oleh mahasiswa dalam suatu kelas.

\section{KESIMPULAN}

Pada Perguruan Tinggi Raharja, khususnya pada kelas iLearning, kegiatan diskusi antara mahasiswa dan dosen masih belum berkembang karena diskusi masih di lakukan secara langsung atau tatap muka sehingga proses diskusi pembelajaran kurang maksimal, karena diskusi hanya berlangsung selama perkuliahan berlangsung. Dengan adanya pemanfaatan dari salah satu Google System yaitu RinfoGroups diharapkan proses diskusi pembelajaran menjadi lebih efektif dan efisien dimana proses berdiskusi dapat di akses dimana dan kapan saja, sehingga memudahkan mahasiswa mendapatkan informasi terbaru mengenai perkuliahan. Pemanfaatan RinfoGroups ini di harapkan dapat menjadi wadah diskusi formal pada kelas iLearning sehingga dapat meningkatkan kualitas informasi pada Perguruan Tinggi Raharja. Adapun kelebihan yang di dapat dengan menggunakan RinfoGroups yaitu bersifat Online, dapat 
diakses dimana dan kapan saja, tidak perlu mendaftar jika ingin masuk ke Grup diskusi, hanya perlu memiliki akun Rinfo, dapat terhubung dengan RinfoApps lainnya, mempermudah interaksi antara mahasiswa dan dosen di luar jam perkulihaan dan yang terakhir memudahkan dosen sharing materi perkuliahan. Selain kelebihan tersebut, terdapat kekurangan dari pemanfaatan RinfoGroups yaitu yang pertama harus terkoneksi dengan internet dan yang kedua pesan dalam grup diskusi dapat tercampur email lain yang ada di dalam inbox.

\section{SARAN}

Pemanfaatan RinfoGroups sebagai media diskusi online sudah di terapkan dan dapat menjadi wadah berdiskusi formal pada perguruan tinggi raharja. Akan tetapi, setelah melakukan analisa terhadap pemanfaatan dari RinfoGroups penulis menyadari terdapat beberapa kekurangan dari system ini. Terdapat beberapa hal yang dapat dijadikan saran dari penulis untuk pengembangan berikutnya yaitu : adanya sebuah use case diagram dan juga activity diagram yang dapat menggambarkan proses berjalannya sistem, mulai dari request grup diskusi sampai mahasiswa dan dosen dapat berdiskusi hanya dengan membuka email Rinfo.

\section{UCAPAN TERIMA KASIH}

Pada kesempatan ini, Penulis ingin mengucapkan terimakasih kepada Allah SWT yang telah memberikan sehat jasmani dan rohani sehingga penulis dapat menyelesaikan penelitian ini. Untuk dosen pembimbing yang tidak mengenal lelah untuk memberikan arahan serta ilmu nya kepada penulis. Serta Untuk Orang tua dan juga teman-teman yang selalu memberikan motivasi dan saran-saran yang bermanfaat sehingga penulis dapat menyelesaikan penelitian ini

\section{DAFTAR PUSTAKA}

[1]. Rahardja, Untung. 2011. "Definisi iLearning". Raharja Enrichment Centre (REC). Tangerang.

[2]. Martono Aris, Padeli, dan Rosalina Miliartha. (2016). "Rancang-bangun Aplikasi Sistem Diskusi Pembelajaran On-line Pada Perguruan Tinggi”.Jurnal CCIT Vol 9 No.2 ISSN:1978-8282

[3]. Putranto A. (2012). Perancangan Forum Diskusi Mobile Online Learning". Jurnal ComTech Vol.3 No.2, 860-871

[4]. Desrianti Dewi Immaniar, Lusyani Sunarya, dan Dwi Fitri Permania. (2015). "Pemanfaatan Teknologi Komunikasi Dan Informasi (TIK) Pada Rhjfox Sebagai Forum Diskusi”. Jurnal CCIT Vol 8 No.3 ISSN : 1978-8282

[ 5]. Yuniati, S. (2012). Peta Konsep (Mind Mapping) dalam Pembelajaran Struktur Aljabar. Gamatika, 3(2).

[6]. Nida, Yessy "Metode Frecilia. Observasi". https://widuri.raharja.info/index.php/Metode Observasi . diakses tanggal 11 Juni 2017.

[7]. Rusnandi, Enang, and Deffy Susanti. "Perencanaan Strategis Cloud Computing Technology Berbasis Gafe (Google Apps For Education) Bagi Perguruan Tinggi Swasta Di Wilayah Iii Cirebon Propinsi Jawa Barat." Jurnal Computech \& Bisnis 6.1 (2012): 116.

[ 8]. Rahardja Untung, Indri Handayani, dan Baiq Aneji Pahad. (Oktober 2016). "Pemanfaatan Rinfoform Sebagai Media Update Artikel Pada iRan". Jurnal CSRID Vol.8 No.3

[9]. Filja, Chasfriati, Mardhiah Fadli, dan Syefrida Yulina.(2016). "Sistem Informasi Penilaian Partisipasi Mahasiswa dalam Berdiskusi Secara Online Menggunakan Metode Content Analysis." Jurnal Aksara Komputer Terapan Vol.5 No.1 
Pemanfaatan Rinfogroup Sebagai Media Diskusi ...

[10]. Handayani, Indri, Qurotul Aini, and Yessy Oktavyanti. (2015) "Penggunaan RinfoCal Sebagai Aplikasi Pengingat (Reminder) Kegiatan Akademik Pada Perguruan Tinggi." Jurnal CCIT Vol. 9

[11]. Handayani, I., Kusumahati, H., \& Badriah, A. N. (2017). Pemanfaatan Google Spreadsheet Sebagai Media Pembuatan Dashboard pada Official Site iFacility di Perguruan Tinggi. SISFOTENIKA, 7(2), 177-186. 